2

EGG-WTD-10635

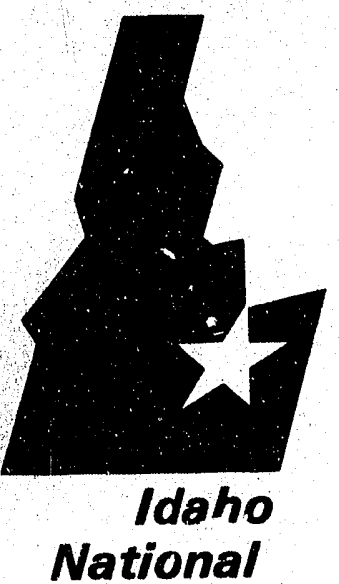

Engineering

Laboratory

Managed

by the U.S.

Department

of Energy

\section{Test Plan for Engineering Scale} Electrostatic Enclosure Demonstration
L. C. Meyer

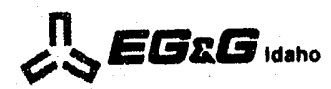

Work performed under DOE Contract No. DE-AC07-76IDO1570
February 1993 
This document contains new concepts or the author(s) interpretation of new calculations and/or measurements; accordingly, EG\&G Idaho, Inc. is required by the United States Government to include the following disclaimer:

\section{DISCLAIMER}

This report was prepared as an account of work sponsored by an agency of the United States Government. Neither the United States Government nor any agency thereof. nor any of their employees, makes any warranty, express or implied. or assumes any legal liability or responsibility for the accuracy, completeness, or usefulness of any intormation, apparatus, product or process disclosed, or represents that its use would not intringe privately owned rights. References herein to any specific commercial product. process, or service by trade name, trademark. manutacturer, or othenwise, does not necessarily constitute or imply its endorsement. recommendation, or favoring by the United States Government or any agency thereot. The views and opinions of authors expressed herein do not necessarily state or reflect those of the United States Government or any agency thereot. 


\title{
Test Plan for Engineering Scale Electrostatic Enclosure Demonstration
}

\author{
L. C. Meyer
}

Published February 1993

\author{
Idaho National Engineering Laboratory \\ EG\&G Idaho, Inc. \\ Idaho Falls, Idaho 83415
}

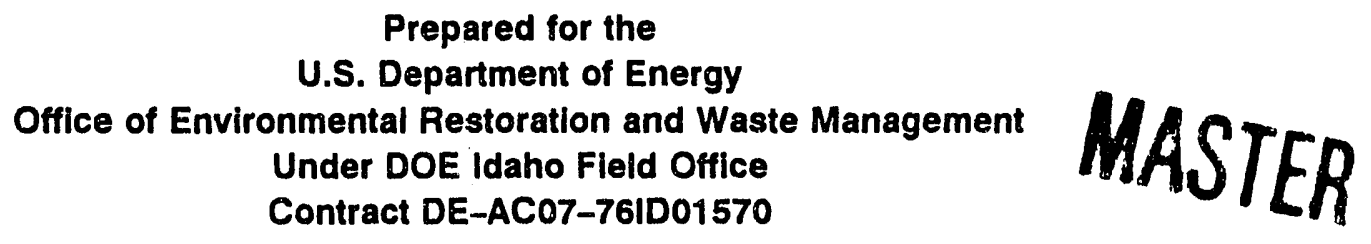


Test Plan for Engineering Scale Electrostatic Enclosure Demonstration

EGG-WTD-10635

Reviewed by

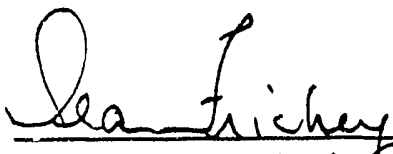

Dean Frickey, Engineering Specialist

Approved by

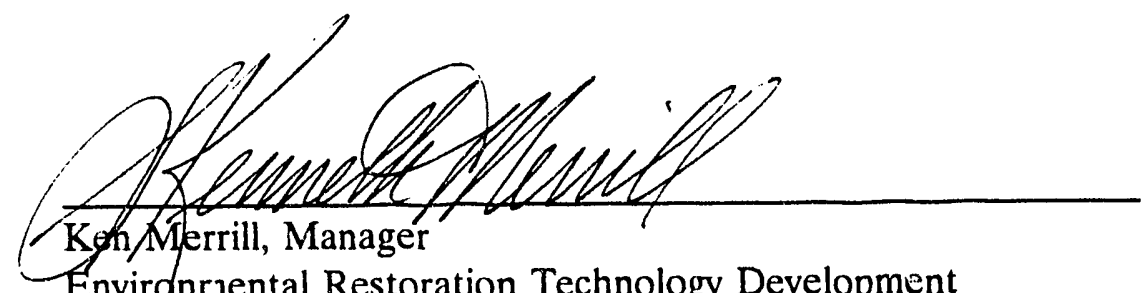

Envirqnreental Restoration Technology Development

Program Unit

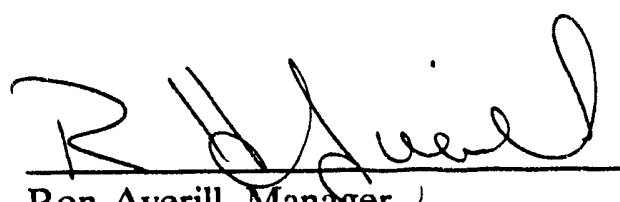

Ron Averill, Manager

Measurement Systems Engineering
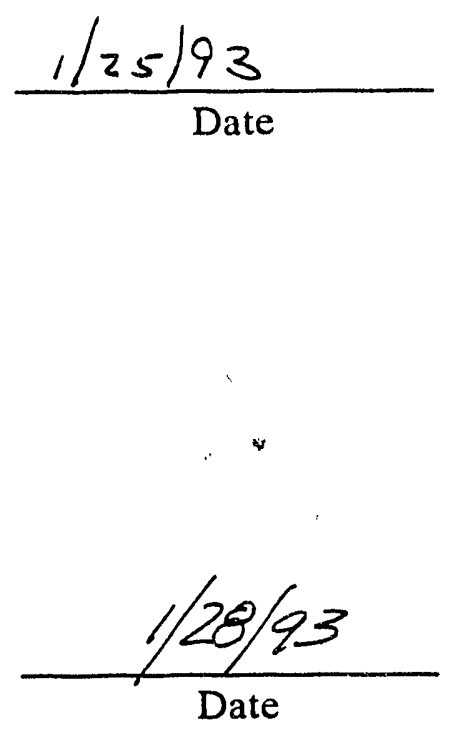

$\frac{25 \operatorname{JAN} 93}{\text { Date }}$

ii 


\begin{abstract}
This test plan describes experimental details of an engineering-scale electrostatic enclosure demonstration to be performed at the Idaho National Engineering Laboratory in fiscal year (FY)-93. This demonstration will investigate, in the engineering scale, the feasibility of using electrostatic enclosures and devices to control the spread of contaminants during transuranic waste handling operations. Test objectives, detailed experimental procedures, and data quality objectives necessary to perform the FY-93 experiments are included in this plan.
\end{abstract}




\section{SUMMARY}

This test plan is for an electrostatic curtain (ESC) demonstration that is being performed at the Idaho National Engineering Laboratory (INEL) as part of the Buried Waste Integrated Demonstration (BWID) Project under the Retrieval Related Technologies, Techrical Task Plan, TTP-ID 132007. BWID examines promising technologies for demonstration purposes and also develops new technologies for application to U. S. Department of Energy (DOE) sites' waste problems.

The ESC research project was started in fiscal year (FY)-90 as a promising component of an overall contamination control scheme for use during retrieval of buried transuranic (TRU) waste. ESCs were examined as possible collectors or repellers of plutonium/americium particles or soil contaminated with plutonium/americium particles.

The objectives of this demonstration are to show the effectiveness of ESCs for controlling the spread of TRU contamination during waste handling operations. The effectiveness is assessed by computing the removal of plutonium/americium contaminated dusts from aerosolized soil thus representing a worst case TRU handling operation, such as retrieval of buried waste. A successful demonstration would show that $98 \%$ of the activity present in an original dust cloud were removed by the combined electrostatic control apparatus. The removal efficiency will be determined from cyclone sampler data taken at the inlet and outlet of the test section. The equation for removal efficiency is

Removal efficiency \% $=\left[\left(\mathrm{P}_{\text {in }}-\mathrm{P}_{\text {out }}\right) / \mathrm{P}_{\text {in }}\right] * 100$

The experiments will be run with poly dispersed $\mathrm{PuO}_{2}$ blended with INEL soil so that the mixture has less than $2 \mathrm{nCi} / \mathrm{g}$ activity. The poly dispersed $\mathrm{PuO}_{2}$ will provide a range of particles sizes for use in evaluating efficiency of the ESC separation process. The $\mathrm{PuO}_{2}$ blended INEL soil will be prepared by the Inhalation Toxicology Research Institute at Albuquerque, New Mexico.

The demonstration is contained within a Perma-con stainless steel enclosure. A ventilation system provides negative pressure inside the Perma-con enclosure during the experiment runs. Part of the outlet ventilation system containing a test section is also located in the Perma-con enclosure and interfaces with a Nuclear Power Outfitters inner frame and tent. The ventilation system test section allows for inserting interchangeable electrostatic test fixtures into the duct. The electrostatic test apparatus includes a set of parallel plates, cathode ray tube, and electret filter. These devices will be used in three separate parts of the test demonstration to remove plutonium from the aerosol in the duct.

The demonstration tests inside the inner enclosure include construction grade enclosure materials made of stainless steel and a conductive fabric. The previous glove box tests indicated that a grounded and electrically conductive material collected the least amount of contamination. An insulation material, such as polyethylene, will be used for comparison. This part of the test should demonstrate that the minimal amount of decontamination is required when using a grounded electrically conductive material for an enclosure. The material decontamination factor is calculated by 
Material decontamination factor $\%=[(\mathrm{IM}-\mathrm{CM}) / \mathrm{MM}]{ }^{*} 100$

where

$$
\begin{aligned}
& \mathrm{IM}=\mu \mathrm{Ci} / \mathrm{g} \text { of }{ }^{239} \mathrm{Pu} \text { on insulation material } \\
& \mathrm{CM}=\mu \mathrm{C}: / \mathrm{g} \text { of }{ }^{239} \mathrm{Pu} \text { on grounded conductor material. }
\end{aligned}
$$

Work done under the contamination control research project studies such as the electrostatic enclosure research will eliminate unknowns in the body of knowledge about the retrieval options for buried TRU waste at the INEL. This information will be factored into a remedial investigation/ feasibility study leading to a final record of decision for disposition of the buried TRU waste. 


\section{CONTENTS}

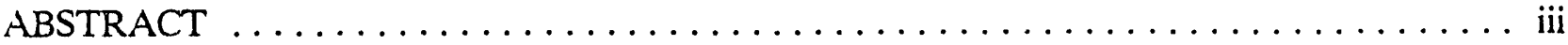

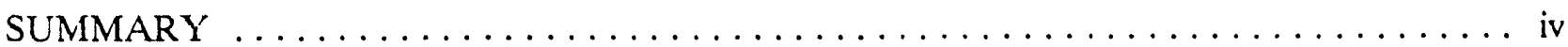

ACRONYMS $\ldots \ldots \ldots \ldots \ldots \ldots \ldots \ldots \ldots \ldots \ldots \ldots \ldots \ldots \ldots \ldots \ldots \ldots \ldots \ldots$ viii

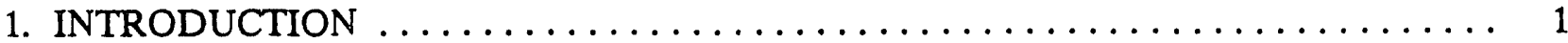

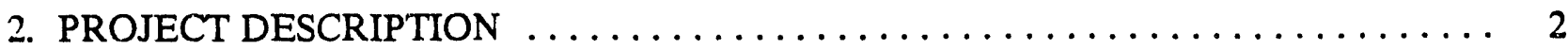

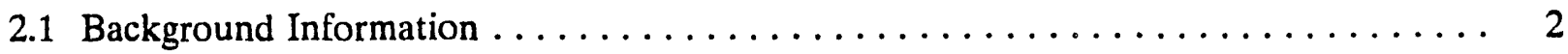

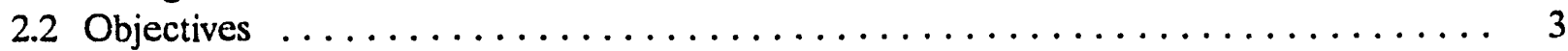

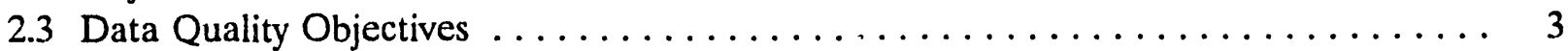

3. PROJECT ORGANIZATION $\ldots \ldots \ldots \ldots \ldots \ldots \ldots \ldots \ldots \ldots \ldots \ldots \ldots \ldots$

4. EXPERIMENTAL PLAN $\ldots \ldots \ldots \ldots \ldots \ldots \ldots \ldots \ldots \ldots \ldots \ldots \ldots \ldots \ldots \ldots$

4.1 ESC Test Configurations $\ldots \ldots \ldots \ldots \ldots \ldots \ldots \ldots \ldots \ldots \ldots \ldots \ldots \ldots \ldots$

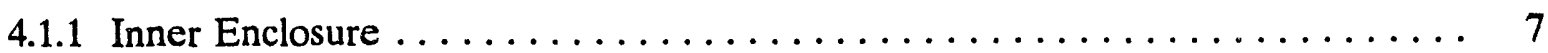

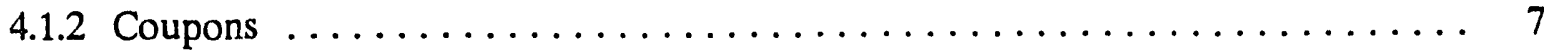

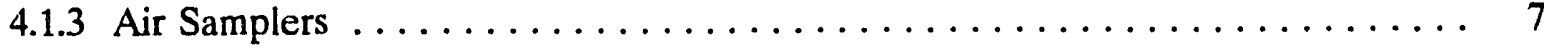

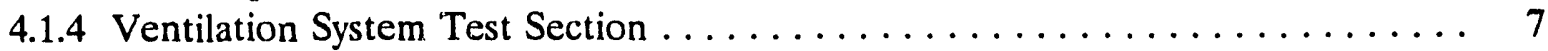

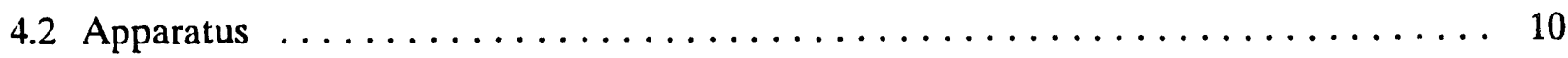

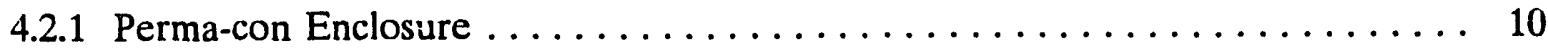

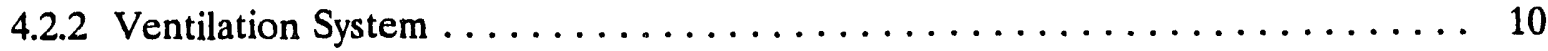

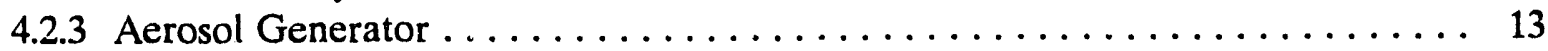

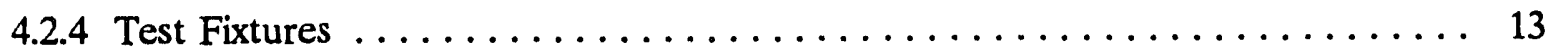

4.2.5 Supporting Electrical Equipment $\ldots \ldots \ldots \ldots \ldots \ldots \ldots \ldots \ldots \ldots \ldots \ldots \ldots$

4.3 Particulate Sample Filters $\ldots \ldots \ldots \ldots \ldots \ldots \ldots \ldots \ldots \ldots \ldots \ldots \ldots \ldots \ldots \ldots$

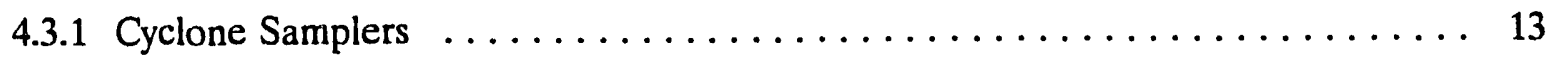

4.3 .2 Low Volume Cascade Impactor $\ldots \ldots \ldots \ldots \ldots \ldots \ldots \ldots \ldots \ldots \ldots \ldots \ldots$

4.4 Laboratory Instruments $\ldots \ldots \ldots \ldots \ldots \ldots \ldots \ldots \ldots \ldots \ldots \ldots \ldots \ldots \ldots \ldots$

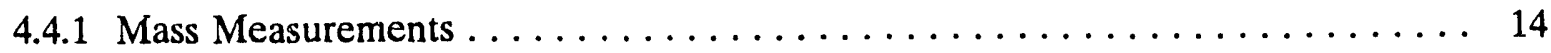

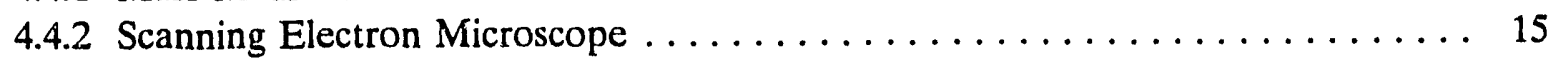

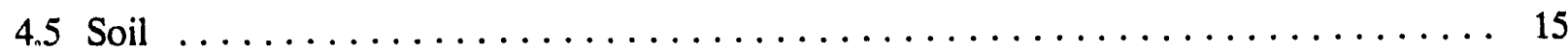


5. TEST PROCEDURES $\ldots \ldots \ldots \ldots \ldots \ldots \ldots \ldots \ldots \ldots \ldots \ldots \ldots \ldots \ldots$

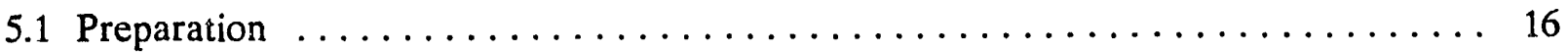

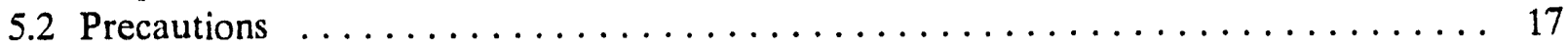

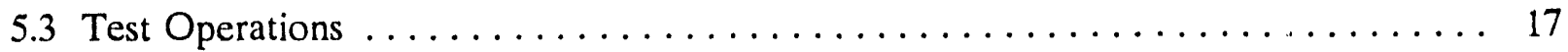

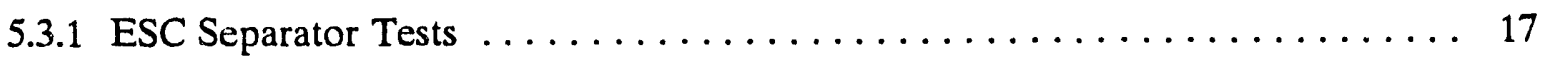

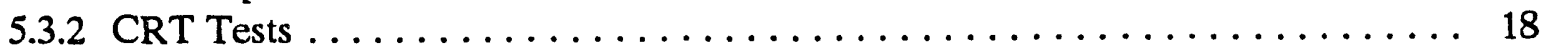

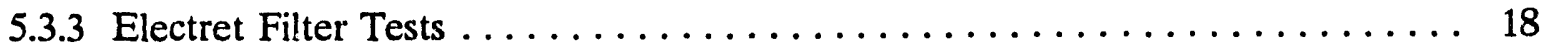

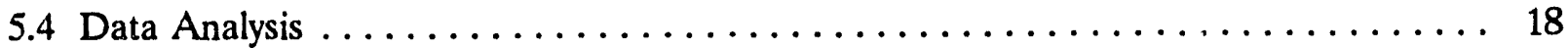

6. SAMPLE CONTROL AND DOCUMENT MANAGEMENT $\ldots \ldots \ldots \ldots \ldots \ldots$

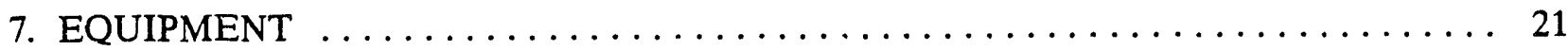

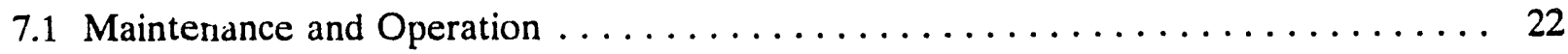

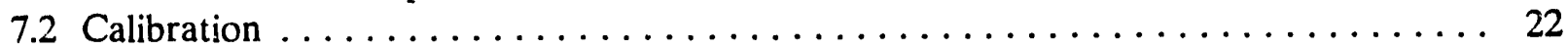

8. ANALYTICAL PROCEDURES $\ldots \ldots \ldots \ldots \ldots \ldots \ldots \ldots \ldots \ldots \ldots \ldots \ldots \ldots$

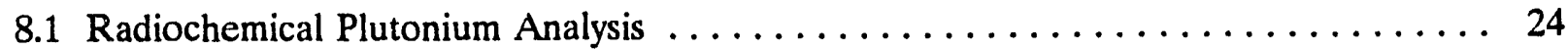

8.2 Plutonium Analysis by Large Area Alpha Spectrometry $\ldots \ldots \ldots \ldots \ldots \ldots \ldots \ldots$

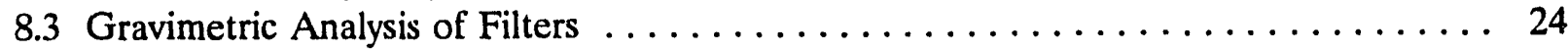

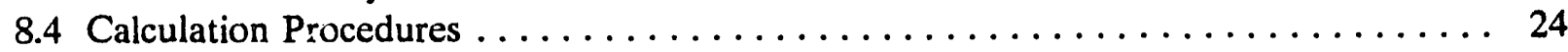

9. DATA MANAGEMENT AND ANALYSIS $\ldots \ldots \ldots \ldots \ldots \ldots \ldots \ldots \ldots \ldots \ldots$

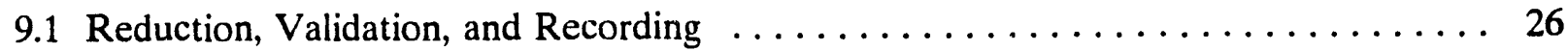

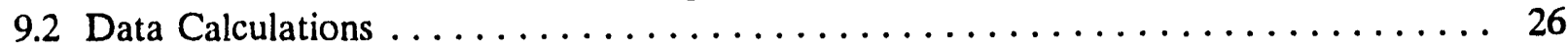

10. QUALITY ASSURANCE $\ldots \ldots \ldots \ldots \ldots \ldots \ldots \ldots \ldots \ldots \ldots \ldots \ldots \ldots$

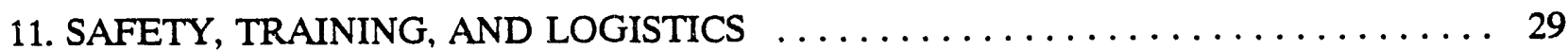

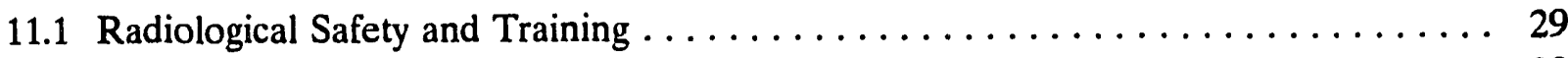

11.2 Laboratory Safety and Training . . . . . . . . . . . . . . . . . . . . 29

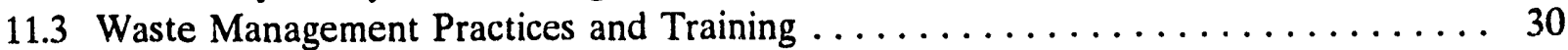

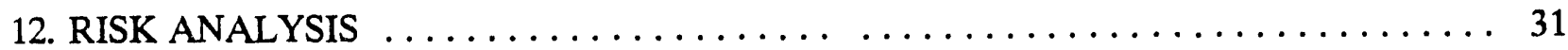

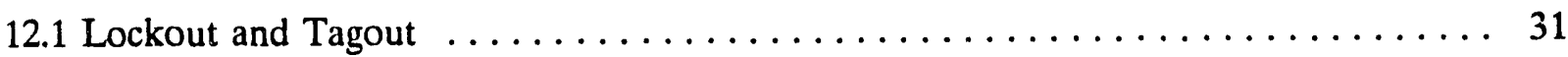

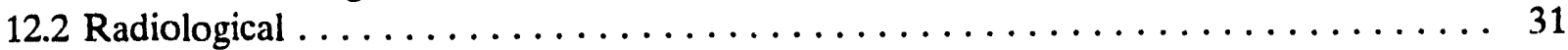

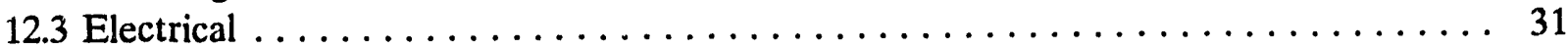

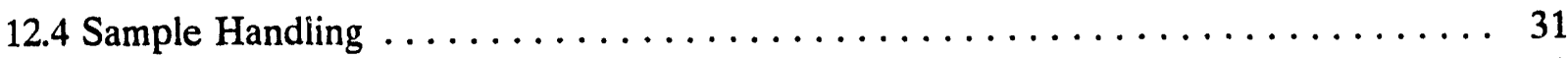

12.5 Transportation Between Experiment and Laboratory . . . . . . . . . . 32 


\section{FIGURES}

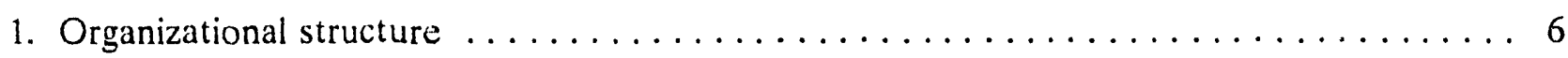

2. Top view of ESC experiment showing Perma-con enclosure, ventilation system, and arrangement of test items $\ldots \ldots \ldots \ldots \ldots \ldots \ldots \ldots \ldots \ldots \ldots \ldots \ldots \ldots$

3. Parallel plate arrangement in duct $\ldots \ldots \ldots \ldots \ldots \ldots \ldots \ldots \ldots \ldots \ldots \ldots$

4. CRT arrangement with duct $\ldots \ldots \ldots \ldots \ldots \ldots \ldots \ldots \ldots \ldots \ldots \ldots \ldots \ldots \ldots \ldots$

5. Electret filter in duct position $\ldots \ldots \ldots \ldots \ldots \ldots \ldots \ldots \ldots \ldots \ldots \ldots \ldots \ldots \ldots \ldots$

\section{TABLES}

1. Size range and ECD for each stage of the low volume cascade impactor 


\section{ACRONYMS}

BWID Buried Waste Integrated Demonstration

CRT Cathode ray tube

DOE U.S. Department of Energy

ECD Effective cutoff diameter

EPA Environmental Protection Agency

ESC Electrostatic curtain

FY Fiscal year

HEPA High efficiency particulate air

INEL Idaho National Engineering Laboratory

MSA Mine Safety Appliance

MTR Materials Test Reactor

RADCON Radiological controls

RCT Radiological controls technician

SEM Scanning electron microscope

TRA Test Reactor Area

TRU Transuranic 


\section{Test Plan for Engineering Scale Electrostatic Enclosure Demonstration}

\section{INTRODUCTION}

This test plan defines experimental details of an engineering scalc electrostatic enclosure demonstration to be performed at the Idaho National Engineering Laboratory's (INEL's) Test Reactor Area (TRA). Electrostatic curtain (ESC) technology may be applied as a contamination control technique during handling of transuranic (TRU) material such as retrieval of buried waste.

Previous studies of electrostatic devices at the INEL include scoping tests (e.g., glove box experiments) that identified electrostatic material devices that could repel or attract plutonium/americium contaminated dust and plutonium/americium particles. ${ }^{1,2}$ Techniques were also developed to characterize size distribution and identify high- $Z$ materials using a cascade impactor and scanning electron microscope (SEM) with bit-mapping. Studies were conducted on separating charged particles in an aerosol, materials for ESCs, and electret filters. The results of these studies were used in a preconceptual design for an electrostatic enclosure. ${ }^{3}$

Based on the previous studies, practical application of this emerging technology in dealing with airhorne radioactive contamination will be demonstrated and experimentally verified in the fiscal year (FY)-93 engineering scale experiments. 


\section{PROJECT DESCRIPTION}

The ESC demonstration is being performed at the INEL as part of the Buried Waste Integrated Demonstration Project (BWID) under the Retrieval Related Technologies, Technical Task Plan TTP-ID-132007. BWID examines promising technologies for demonstration purposes and develops new technologies for application to the U.S. Department of Energy (DOE) sites' waste problems.

The ESC research project was started in FY-90 as a promising component of an overall contamination control scheme for use during retrieval of buried TRU waste. The conceptual design for contamination control during retrieval was developed and included (a) dust control and main senance of the naturally occurring moisture in the waste zone, (b) ventilation of the retrieval area, and (c) rapid detection of contaminants for both airborne and loose contamination. ${ }^{4}$ ESCs were examined as possible collectors or repellers of plutonium/americium particles or soil contaminated with plutonium/americium particles.

During FY-90 and FY-91, several promising candidate ESC materials were tested including conductors, antistatic, and insulators. ${ }^{1}$ In addition, techniques were developed to measure particle size distribution and plutonium/americium particle identification. These techniques were used to evaluate the effectiveness of the curtains.

Work done under the contamination control research project studies, such as the electrostatic enclosure research, will eliminate unknown information about the retrieval options for buried TRU waste at the INEL. This information will be factored into a remedial investigation/feasibility study and lead to a final record of decision for disposition of the buried TRU waste.

\subsection{Background Information}

Electrostatic charge can accumulate on materials that are insulators, such as polyethylene plastic, and contribute to the spread of airborne contamination. Electrostatic charge build up can be eliminated by using a conducting material that drains off any accumulated charges. A grounded conducting surface not only collects a minimum amount of dust and contamination but also may discharge any charged particles striking the surface. The FY-90, FY-91, and FY-92 ESC studies demonstrated that a minimum amount of dust and contamination is collected on a surface that is grounded. The results of these studies also showed that the positively charged plutonium and americium particles are strongly attracted to negative surfaces in an electrostatic field. Because a negative surface attracts and a positive surface repels positively charged particles, there is a basis for control of charged airborne particles passing within range of the electric field. The charged particles can be attracted, repelled, or neutralized by using the appropriate surface conditions on the wall of the containment space. This will also be true for combined particles (plutonium attached to dust particles). If plutonium is attached to negatively charged dust particles and the resulting combined charge is negative, the combined particles are attracted to a positive surface and vice versa. If the combined particles have a neutral charge, they would be unaffected by the electric field and be collected by the electret filter [or high efficiency particulate air (HEPA) filter] in the ventilation system outlet. 
Electret filters with high efficiency for collecting submicron particles have been developed to clean air with less pressure drop than purely mechanical filters. ${ }^{5}$ Electret filters were included in the FY-91 ESC glove box experiments and were found to work quite well.

The obvious application of ESCs is to establish enclosure walls that can attract, repel, or neutralize plutonium/americium contaminants. By having a grounded (electrically conductive) surface, charged particles coming in contact with the surface would be discharged with minimum number becoming attached. Additionally, application of electrostatic devices in ventilation systems can promote cleaning of airborne plutonium/americium from the aerosol.

\subsection{Objectives}

The objective of this demonstration is to show the effectiveness of ESCs for controlling the spread of TRU contamination during waste handling operations. The effectiveness is assessed by computing the removal of plutonium/americium contaminated dusts from aerosolized soil thus representing a worst case TRU handling operation, such as retrieval of buried waste. A successful demonstration would show that $98 \%$ of the activity present in an original dust cloud were removed $b_{j}$ the combined electrostatic control apparatus. ${ }^{a}$ Detailed objectives include

- Evaluate the use of conducting fabric and hardwall material for construction of enclosures. This demonstrates the advantages of a conducting surface for contamination control by comparing the results with that of a insulator material such as polyethylene.

- Study the feasibility of using electrostatics to separate ${ }^{239} \mathrm{Pu}$ from dust particles in an aerosol such as in a ventilation system before HEPA filtration. This can be accomplished with a parallel plate separator in the ventilation duct that has negatively charged plates and grounded plates alternately placed in the duct.

- Investigate electret filters for possible use in the ventilation system for removing particulates and radioactive particles. This type of filter has less air resistance than mechanical filters.

\subsection{Data Quality Objectives}

The data quality objectives include a peer review by a knowledgeable person of the data, assumptions, and methodology and individual measurement analysis to verify that the data are within the performance specification as detailed in this test plan. The following accuracy specifications apply:

- $\quad$ Flow measurements shall be within $\pm 10 \%$

- Mass measurements shall be within $\pm 0.0001 \mathrm{~g}$

a. The $98 \%$ represents removing activity from a source term of $100 \mathrm{nCi} / \mathrm{g}$ down to $2 \mathrm{nCi} / \mathrm{g}$, which is the lower limit definition for radioactive material according to the Department of Transportation definition from 49 CFR 173.401(y). 
- Voltage measurements shall be within $\pm 2 \%$

- Electrical field measurements shall be within $\pm 10 \%$

- Replication of coupon samples shall be four unless otherwise specified

- $\quad$ SEM accuracy will be determined by mode used and reported with analysis

- Radiochemical analysis accuracy will be determined by the laboratory and analytical methods used and reported with the data. At a minimum, the count time must be sufficient to bring the uncertainty below $50 \%$ with a $90 \%$ confidence level $(1.65 \mathrm{o})$. 


\section{PROJECT ORGANIZATION}

The general organization and responsibilities for the key personnel are shown in Figure 1. In addition to the waste engineering personnel, the Radiation Measurements group at TRA will support the tests by providing the facilities, equipment, and supporting personnel and will provide radiochemical analysis. If the radiochemistry cannot be done at TRA in a reasonable time frame, the samples will be sent to UNC Geotech in Grand Junction, Colorado.

The radiological controls technician (RCT) is responsible for the radiological monitoring of the area during all activities at TRA and issuing of green tags for radiologically clean samples. The RCT will assist the personnel with the monitoring of the area and will verify that all personnel are wearing proper dosimetry while at the TRA. The RCT's responsibilities include (a) maintaining the calibration of all radiological instruments and maintaining calibration logbooks, (b) sounding the alarm in the event of a radioactive release, (c) conducting radiological surveys of data collection equipment before and following decontamination procedures, and (d) notifying appropriate emergency personnel on the event of a release, fire, or explosion.

The ESC research will be performed by Measurement Systems Engineering personnel who have experience in measurements and electrical science. This group was responsible for the FY-90 proof-of-principal ESC experiments and the FY-91 and FY-92 ESC studies and associated analysis. 


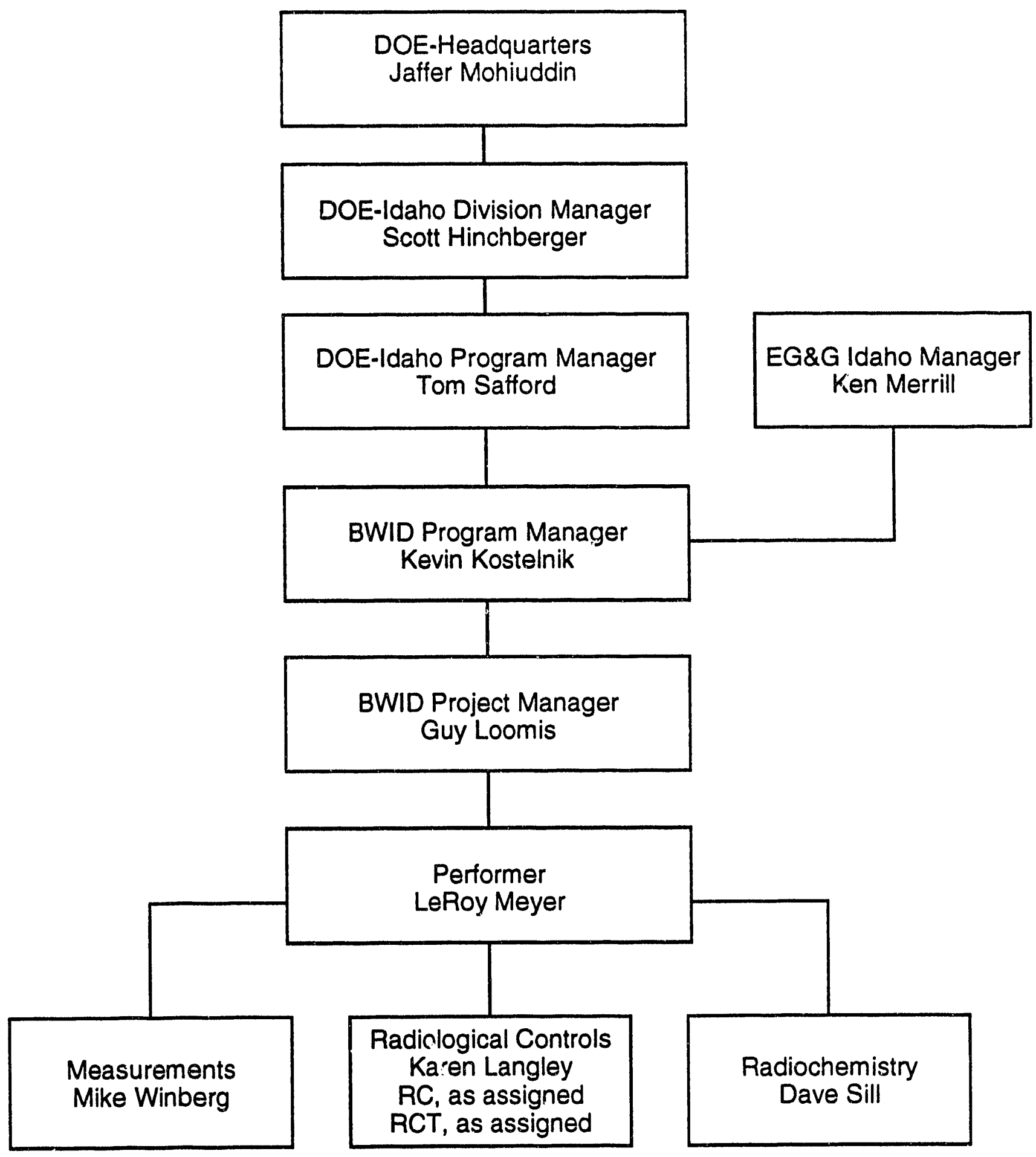

Figure 1. Organizational structure. 


\section{EXPERIMENTAL PLAN}

This section contains experimental details describing how and what data will be collected during the experiments described in Section 2. The ESC devices consist of parallel arrangements of metal plates, $3 \mathrm{M}$ electret filter material, polyethylene sheet material, electrically conductive building fabric material, and stainless steel sheets. The following is a description of the test configuration, supporting apparatus, and type of data expected.

\subsection{ESC Test Configurations}

The ESC experiment layout showing the Perma-con enclosure, inner enclosure, ventilation system, locations of the various test items, and filters is shown in Figure 2. The outer enclosure consists of a $12 \times 8$-ft stainless steel Perma-con structure that has an air intake with a HEPA filter in the center front panel and panels with personnel doors on each side. Each door also has a HEPA filter. The center panel will have two glove ports and feedthroughs for cables and hoses.

\subsubsection{Inner Enclosure}

The inner enclosure consists of a Nuclear Power Outfitters containment tent and support frame. Each of the side curtains will have an air vent opening with a HEPA filter to allow air to enter the center section and keep each of the side areas clean. On side $A$ of the inner enclosure will be a $6 \times 6$-ft conductive material sheet, and side $\mathrm{B}$ will be a $6 \times 6$-ft polyethylene sheet. The center test panel will be a $3 \times 6$-ft sheet of stainless steel. Glove ports will be made in the inner plastic liner to recover sample coupons.

\subsubsection{Coupons}

For each test run, four polyethylene coupons (each 4 in. $^{2}$ in size) will be placed on the polyethylene sheet for analysis. Similarly, four coupons of the conductive material will be placed on the conductive sheet for analysis and four stainless steel coupons on the stainless steel sheet.

\subsubsection{Air Samplers}

Air samplers will be placed in the five locations shown in Figure 2 including above the dust generator and at the intake and output of the ventilation system test section. The air samplers will operate for each test.

\subsubsection{Ventilation System Test Section}

The test section in the ventilation system has interchangeable test fixtures for the parallel plates, CRT, and electret filter tests.

4.1.4.1 Parallel Plate Tests. The parallel plate test configuration mounted in the ventilation system is shown in Figure 3. This test utilizes the ventilation system, electrostatic enclosure, separator plate assembly, and aerosol generator. The aerosol will be generated in the enclosure and will be drawn through the ESC separator plates by the ventilation system fan. The separator consists of 


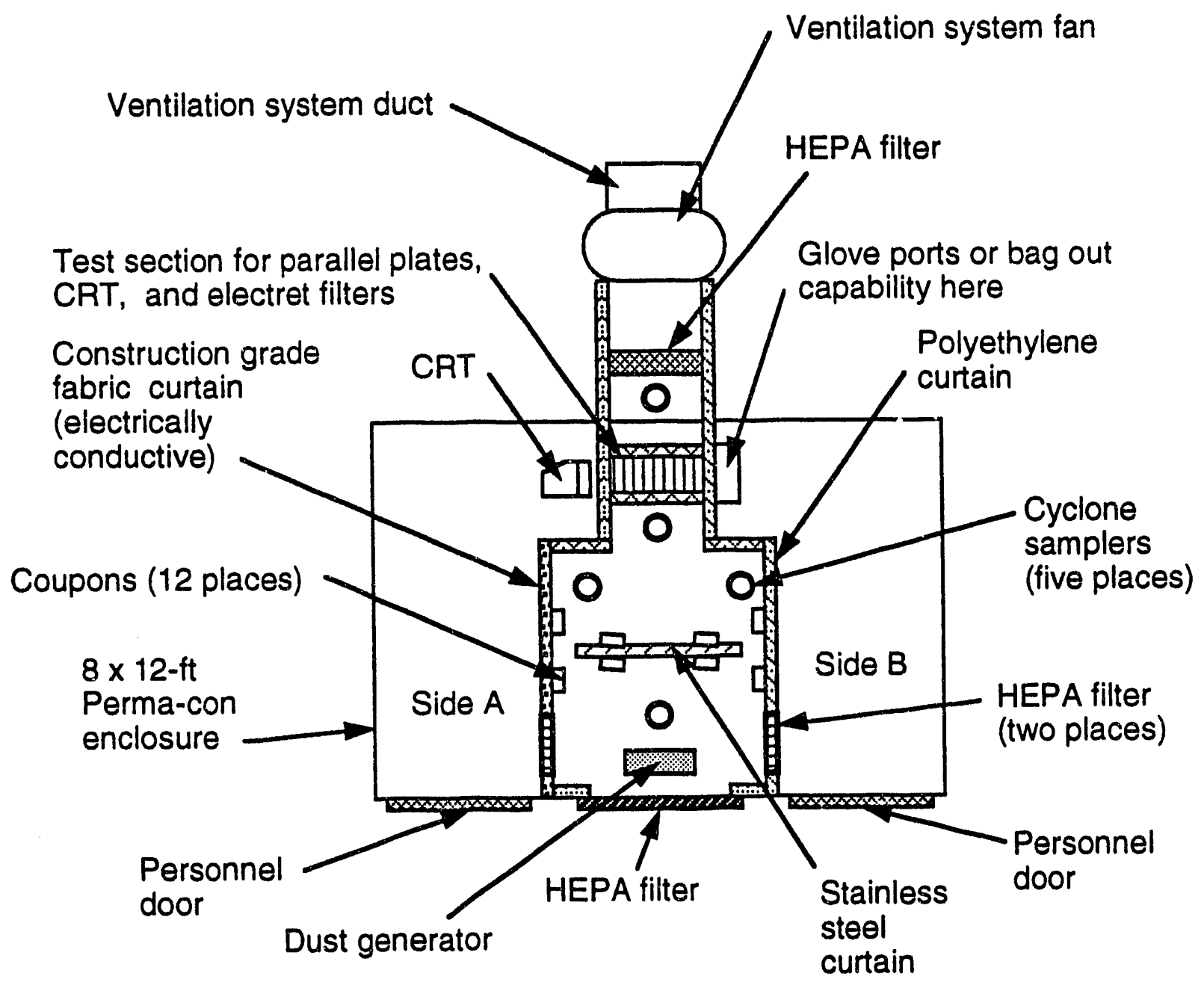

Figure 2. Top view of ESC experiment showing Perma-con enclosure, ventilation system, and arrangement of test items. 


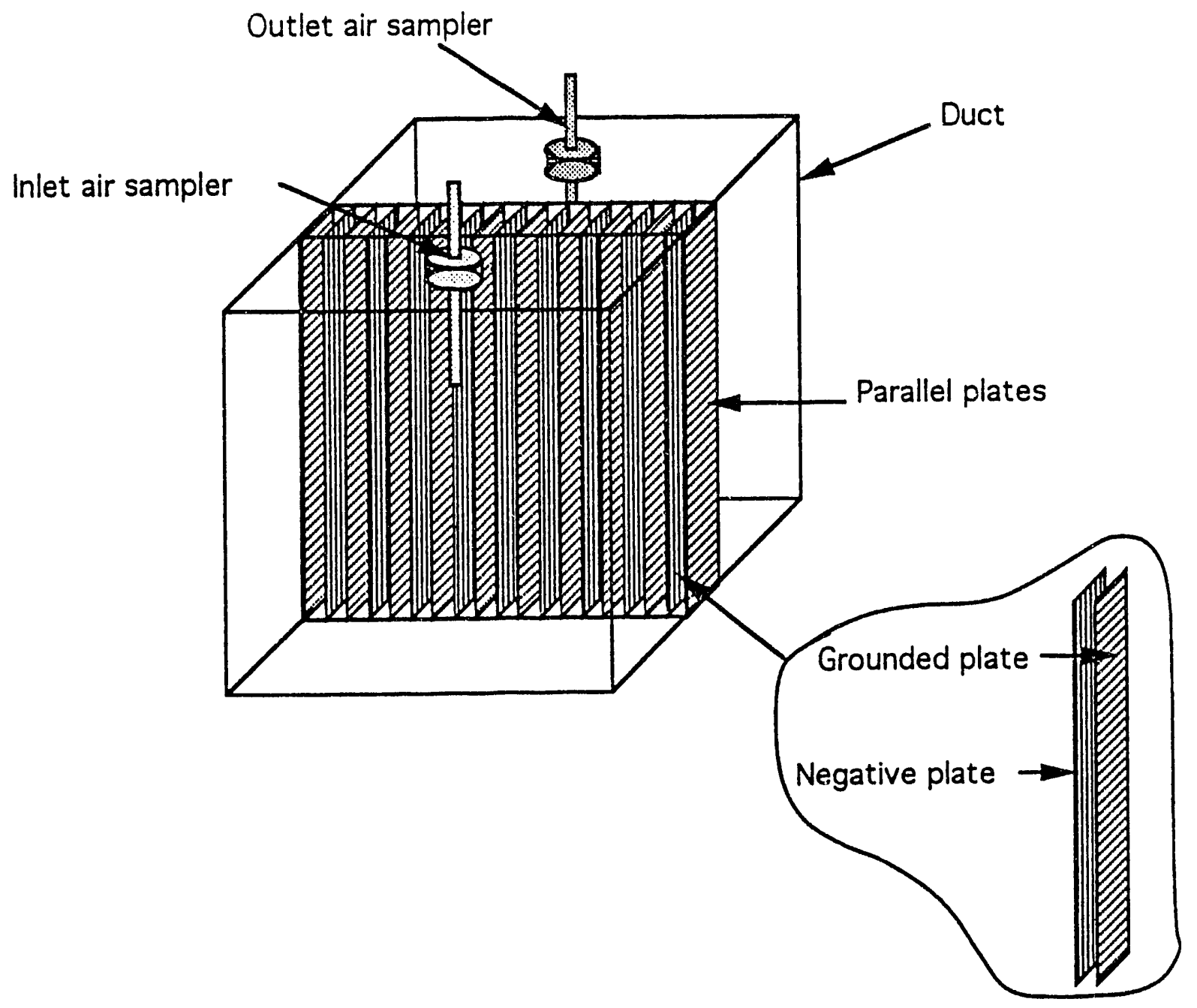

Figure 3. Parallel plate arrangement in duct. 
parallel plates that have the outside plates and odd numbered plates grounded. The even numbered plates will have a negative voltage. The number of plates, spacing, and voltage may vary depending on the characteristics of the soil blend used. The spacing can be changed in increments of $1 \mathrm{~cm}$. The power supply can also be varied to provide any voltage between zero and $600 \mathrm{~V}$.

4.1.4.2 Tests Using a CRT as the Electric Field Source. The test fixture arrangement using a CRT as the electric field source is shown in Figure 4. The CRT has a static charge of about 14,000 $\mathrm{V}$ at the face. A polyethylene film will be across the face to collect the positive particles because the screen has a negative charge. A grounded plate placed on the opposite side of the ventilation test section about $2 \mathrm{ft}$ from the CRT will provide an average electric field across the test section of about $230 \mathrm{~V} / \mathrm{cm}$. Coupons will be placed on the plastic sheet to collect samples for gravimetric, radiochemical, and SEM analysis. In addition, samples will be taken from the five air samplers.

4.1.4.3 Electret Filter Tests. Electret filters will be obtained in a size that fits in the ductwork test section as shown in Figure 5. The electret filters will be tested to determine how well they remove radioactive particles from the aerosol by analyzing the air samples taken at the intake and outlet of the test section. In addition, the cascade impactor will be placed on the outlet side of the electret filter to determine the size range of any particles that get through. The other three air samplers will collect samples for analysis, and a small piece of the filter will be looked at with the SEM.

\subsection{Apparatus}

The apparatus to be used for the ESC engineering scale tests consists of a Perma-con stainless steel enclosure; an aerosol generator for aerosolizing dust; sample holders; test fixtures for parallel plates, electret filters, and CRT for an electrostatic field source; a ventilation system for the entire test enclosure; and a power supply with associated wiring.

\subsubsection{Perma-con Enclosure}

The Perma-con enclosure is 8-ft wide, 8-ft high, and 12-ft long and has a personnel door and two window ports on each side. Inlet and exhaust air are filtered minimizing the affect on (a) experimental error caused by particulates in the inlet air and (b) impact on room air caused by the exhaust air. Linear flow through the enclosure can be controlled from zero to approximately 40 linear feet per minute (fpm) through the use of the ventilation system fan.

\subsubsection{Ventilation System}

The ventilation system was designed and built at the INEL to simulate certain airflow features of an inner containment building. The duct connecting to the Perma-con enclosure is $24 \times 24$ in. $^{2}$ and has a HEPA filter at the end before the variable speed, induced draft fan that generates airflow in the duct. A differential pressure gauge is across the HEPA filter to help determine when to change the filter. Exhaust air goes into the laboratory, room 101, in the Materials Test Reactor (MTR)-654. 


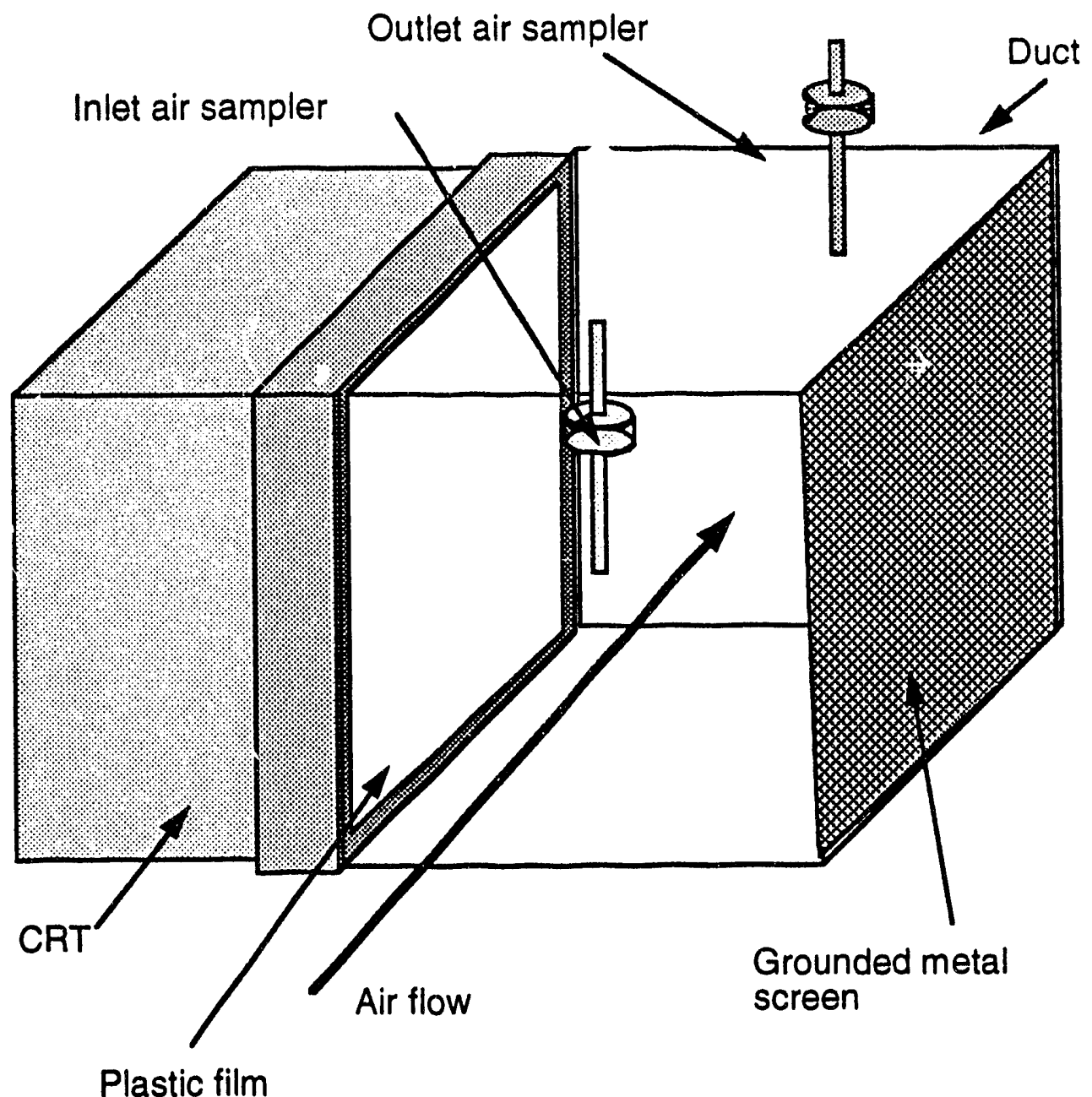

Figure 4. CRT arrangement with duct. 


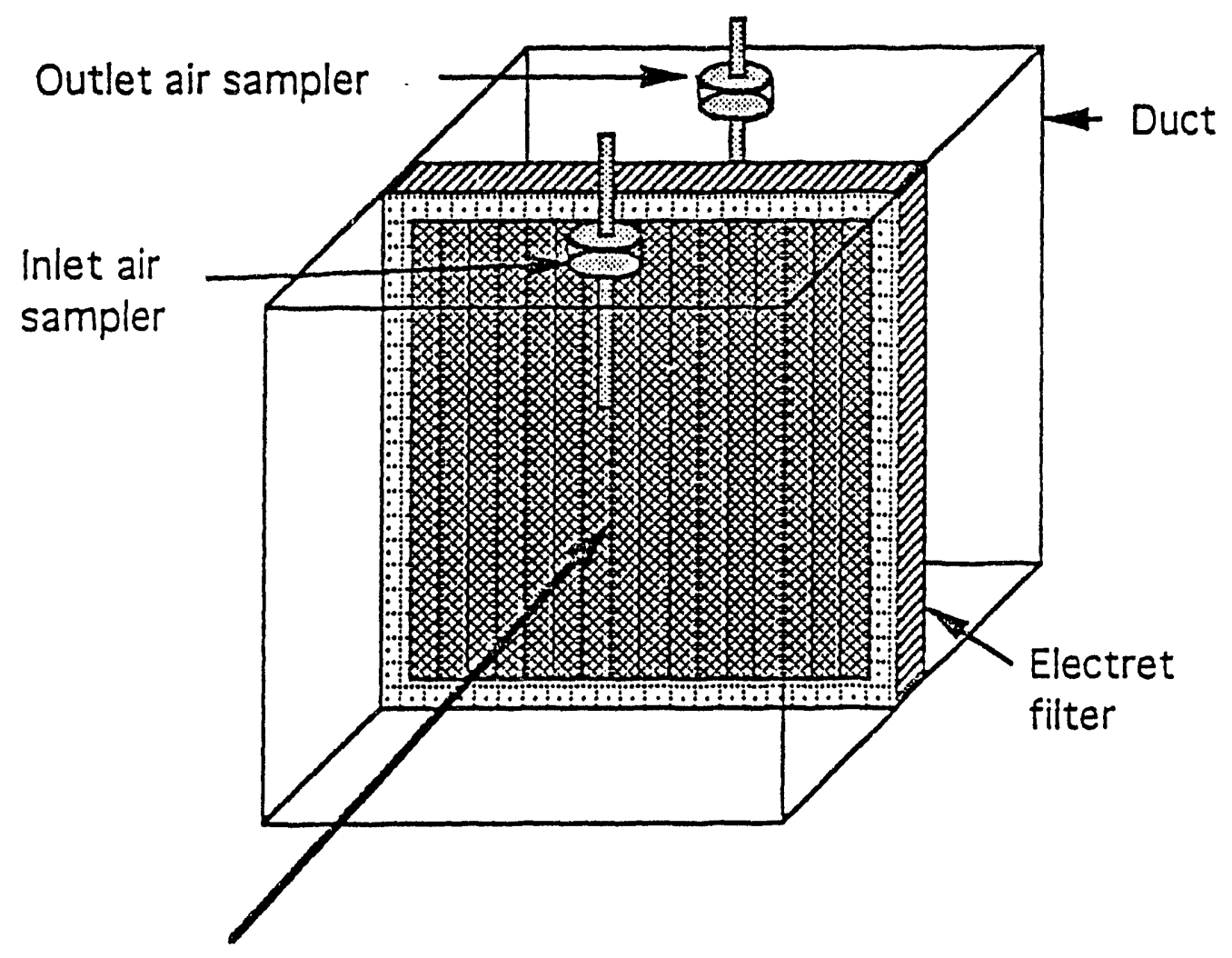

Air flow

Figure 5. Electret filter in duct position. 


\subsubsection{Aerosol Generator}

Dust is generated by blowing pressurized air through a Dacron tube that has numerous holes in it. This tube is placed in the bottom of the V-shaped dust generator, and the air blows through the soil suspending the fines in the air. The suspended soil fines are blown upivard and laterally by the air coming from the holes that are both radially and laterally placed in the tubing.

\subsubsection{Test Fixtures}

Fixtures for the parallel plates, electret filter, and CRT experiments are designed as interchangeable test sections to fit in the ventilation duct at outlet from the Perma-con building.

\subsubsection{Supporting Electrical Equipment}

The supporting electrical equipment includes $300 \mathrm{~V}$ power supplies, control switches, pulse generator, current limiting resistors, ground cable, and hookup wires.

\subsection{Particulate Sample Filters}

The particulate sampling filters consist of the cyclone samplers and Andersen cascade impactor.

\subsubsection{Cyclone Samplers}

Respirable and nonrespirable dust fractions are sampled using Mine Safety Appliance (MSA) cyclone samplers, model 456-243 (referred to in this report as cyclone samplers). Airflow through the cyclone sampler is measured by rotometers and is supplied by a 5 cubic feet per minute (cfm) rotary vane pump. Total dust loading of the atmosphere in the Perma-con enclosure is sampled using a 2-in. particulate filter operated at $2 \mathrm{cfm}$. Exhaust air goes into room 101 in MTR-654.

\subsubsection{Low Volume Cascade Impactor}

The Andersen 1 AFCM ambient particle sizing sampler is a multistage, multiorifice cascade impactor used to measure the size distribution and total concentration levels of particulate matter. It consists of a preseparator, eight orifice stages, a back up filter, and a vacuum pump.

The preseparator is an impaction chamber with one 0.53 -in. diameter inlet orifice and three outlet tubes. The outlet tubes are 1 in. above the impaction surface. This design results in low turbulence and allows collection of several grams of particulate without overloading the preseparator.

Ambient air with aerosol particles enter the inlet cone of the preseparator and cascade through the succeeding orifice stages with successively higher orifice velocities from stage zero to stage seven. Successively smaller particles are inertially impacted onto the collection plates. The submicrometer particles that are not collected by the last collection plate are caught in the back-up filter, which is an integral part of the impactor immediately downstream from stage seven. Stage zero is an orifice stage only. Stage eight is a collection stage only. Clean air is carried through the outlet tubing to the vacuum pump and exhausted. 
A constant air sample flow of the Andersen 1 ACFM is provided by a continuous duty, carbon-vane vacuum pump. Flow rate through the impactor is controlled by an adjustable bleed valve on the pump that requires periodic calibration.

After sampling is completed, the sample time is recorded, and the tared collection plates and back-up filter are removed for subsequent gravimetric or chemical determination. Concentration levels are determined, and the size distribution is plotted.

The size range and effective cutoff diameter (ECD) for each stage of the impactor are given in Table 1.

\subsection{Laboratory Instruments}

The laboratory instruments consist of a mass balance and the SEM.

\subsubsection{Mass Measurements}

Coupon and sample weights will be obtained using either a Satorius balance, model AS120, or a Mettler balance, model AJ100. These balances weigh to the nearest 0.1 of a milligram.

Table 1. Size range and ECD for each stage of the low volume cascade impactor.

\begin{tabular}{llc}
\hline Stage & $\begin{array}{c}\text { Size range } \\
\text { (micrometers) }\end{array}$ & $\begin{array}{c}\text { ECD } \\
\text { (micrometers) }\end{array}$ \\
\hline $\begin{array}{l}\text { Pre- } \\
\text { separator }\end{array}$ & 10.0 and above & 10.0 \\
0 & $9.0-10.0$ & 9.0 \\
1 & $5.8-9.0$ & 5.8 \\
2 & $4.7-5.8$ & 4.7 \\
3 & $3.3-4.7$ & 3.3 \\
4 & $2.1-3.3$ & 2.1 \\
5 & $1.1-2.1$ & 1.1 \\
6 & $0.7-1.1$ & 0.7 \\
7 & $0.4-0.7$ & 0.4 \\
Back-up & $0-0.4$ & 0 \\
filter & & \\
\hline
\end{tabular}




\subsubsection{Scanning Electron Microscope}

Filter and ESC samples will be examined with an SEM to determine the composition, size distribution, and shape of the particles. Particles collected on ESC devices will also be scanned with the SEM to determine if they are of the same size distribution as that of the aerosol.

The SEM is a JEOL, model JXA-840, and has the following capabilities:

- Magnification from 10 to $300,000 x$

- Acceleration voltage from 500 to $30,000 \mathrm{~V}$

- Image modes are secondary electron imaging mode, compositional mode using back scattered electrons, and dot mapping using $x$-ray emissions

- Has an energy dispersive spectrometer

- Has a wave length dispersive spectrometer.

\subsection{Soil}

The experiments will be run with poly dispersed $\mathrm{PuO}_{2}$ blended with INEL soil so that the mixture has less than $2 \mathrm{nCi} / \mathrm{g}$ activity. In preparation of the blend, the soil is dried to a low moisture condition (less than 10\% moisture content by weight) that maximizes resuspension of the soil. The poly dispersed $\mathrm{PuO}_{2}$ will provide a range of particle sizes for use in evaluating efficiency of the ESC separation process. The $\mathrm{PuO}_{2}$ blended INEL soil will be prepared by the Inhalation Toxicology Research Institute at Albuquerque, New Mexico. 


\section{TEST PROCEDURES}

Test procedures for the experiments described in Section 4 are given in this section.

\subsection{Preparation}

The containment enclosure will be prepared by first thoroughly cleaning the inside. Next, a plastic sheet will be placed on the floor of the containment enclosure to aid clean up after the test. The $A$ and $B$ side curtains of polyethylene and conductive material will be hung as dividers on each side with coupons attached. They will be part of the inner enclosure. The stainless steel sheet with coupons will be placed in the center of the enclosure. This is followed by placing all the ESC devices in the ventilation test section and installing the HEPA filters. Then, all the ESC devices that are electrically grounded are connected to the ground cable, and the plus or minus $300 \mathrm{~V}$ wires are connected to the appropriate ESC device terminals for electrical connections. When all the ESC devices are in place, photographs will be taken of the test configuration, and all field changes to the test set up will be recorded $\mathrm{ir}_{\mathrm{i}}$ a laboratory notebook.

Next, the particulate sample filters and supporting equipment will be prepared and put in place. Five filters and five Environmental Protection Agency (EPA), nonrespirable cyclone collector caps are preweighted, and al! filter and cap weights are recorded in a laboratory notebook. To use the EPA cyclone sampler, the respirable filter holder is opened, a membrane filter inserted; the filter holder sealed; and a cellulose seal is placed around the filter holder so that the joint is covered. The cellulose band is then allowed to dry. The filter holder is attached to the cyclone body using a small piece of tygon tubing, and the nonrespirable collector cap is screwed onto the cyclone body. A complete sampler is attached to one of the air sampling lines in the containment enclosure. After placing the five cyclone samplers in the predetermined test locations, these positions are recorded in the laboratory notebook.

An Andersen cascade irnpactor will also be used to determine the aerosol particle size distribution. The cascade impactor filters and the back up filter are preweighed. The weights are recorded in the laboratory notebook, and the filters are placed in the holders. In general, the sampling time period for the cascade impactor should be long enough to collect at least $10 \mathrm{mg}$ of particulates on each impactor stage. The primary measurement is the weight of the particle deposition per impactor stage, measured as the difference in weight of the collection substrate before and after sampling. The particle size distribution will be presented as a bar graph showing the percentage of particles in the size range captured by each stage.

All other sample filters and coupons used in the test are preweighed. The weights are recorded, and the filters and coupons are placed in the designated locations for the particular test.

The inlet aerosolizer air hose will be connected to a high pressure air supply (plant compressed air). Flowrate through the tube should be maintained at approximately $6 \mathrm{cfm}$ during a test. During the FY-90 ESC tests, this airflow was sufficient to suspend the soil fines in the glove box as an aerosol. The particulate aerosol generation parameters were experimentally determined during the FY-89 background tests. The following parameters were valid air flow and air pressure in the plastic tubing ( $6 \mathrm{cfm}$ and $30 \mathrm{psig}$ ), Hi-Vol exhaust flow ( 6 to $8 \mathrm{cfm}$ ), and test duration (15 minutes). Lapel 
cyclone sampler flowrate should be 2 liters per minute (lpm), and the 2 -in. particulate filter will operate at $2 \mathrm{cfm}$. All parameters should be recorded and the results signed and dated in a laboratory notebook.

Finally, the soil is placed in the aerosolizer, temperature and humidity readings taken, and containment enclosure sealed. The measurements are recorded in the laboratory notebook.

\subsection{Precautions}

- Respiratory protection will be worn as directed by RADCON personnel when working with the contaminated soils to avoid inhalation of dust.

- Gloves should be worn when handling the soil.

- All waste generated during clean up of the soil after the test should be placed in the compactible waste.

- Negative pressure should be maintained in the enclosure and ventilation system when running the experiment.

\subsection{Test Operations}

The operating procedures for each of the specific tests are covered in this section. Linear air flow through the enclosure will be maximized to allow for worst case dust air loadings.

\subsubsection{ESC Separator Tests}

After following the test preparation steps in Section 5.1 and placing the duct test section, parallel plates, and equipment in the positions shown in Figures 2 and 3, the experiment should be ready to be performed as follows:

1. Turn on the ventilation system fan to establish air flow through the enclosure

2. Turn on the cascade impactor fan

3. Turn on the cyclone samplers

4. Turn on the electrical power to the parallel plates or any other test items requiring electrical power

5. Turn on the air to the aerosolizer

6. The experiment duration will be determined by running a preliminary clean dust test to check out the test set up. Based on the previous glove box tests, it should be approximately 15 to 20 minutes 
7. Shut down the experiment in the reverse order of the start up

8. Remove filter and coupon samples, after weighing place samples in petri dishes, and save for SEM or chemical analysis

9. Recover as much soil as possible during clean up of the enclosure and ventilation test section and place any paper towels used in clean up in the compactible radioactive waste container according to the TRA procedure.

\subsubsection{CRT Tests}

The CRT is placed in the duct position as shown in Figure 4. Steps 1 through 3 and 5 through 9 of the test procedure in Section 5.3.1 are repeated. The data for this test will be the mass loading of dust caught on the plastic screen, inlet and outlet cyclone samplers, cascade impactor filters, and SEM and radiochemical analysis of samples from these filters.

\subsubsection{Electret Filter Tests}

The electret filter is placed in the duct as shown in Figure 2. Steps 1 through 3 and 5 through 9 of the test procedure in Section 5.3.1 are repeated. The data for this test will be the mass loading of dust caught in the electret filter, outlet filter, cascade impactor filters, and SEM and radiochemical analysis of samples from these filters.

\subsection{Data Analysis}

The data analysis includes the following items:

- Coupon samples and filters will be weighed on $\mathrm{a} \pm 0.0001 \mathrm{~g}$ balance.

- Particle size distributions will be determined from cascade impactor filters.

- The SEM will be used to characterize the particle size and composition of the collected dust. This includes further study of the plutonium contaminates that exist primarily as independent particles and those attached to or combined with other materials that make up dust particles.

- Coupon samples and filters will be sent to the radiochemical laboratory for analysis to determine ${ }^{239} \mathrm{Pu}$ content. The radiochemistry will include selected cascade impactor filters for determining ${ }^{239} \mathrm{Pu}$ content of different particle size ranges.

The particle mass data and results of the radiochemical analysis will be presented in the form of tables and bar graphs. The measured amounts of dust and ${ }^{239} \mathrm{Pu}$ from coupons of the different materials will be compared to determine the effectiveness of grounding the conducting materials as compared to the polyethylene (insulation material). The input and output cyclone sampler filters from the ventilation system test section will be used to determine how much ${ }^{239} \mathrm{Pu}$ is removed by the various ESC devices (e.g., plates, CRT, and electret). 


\section{SAMPLE CONTROL AND DOCUMENT MANAGEMENT}

In general, a laboratory notebook will be kept during check-out of experimental apparatus and conducting experiments. As a minimum, specific data included in the laboratory notebook for the experiments are listed below:

- The ESC devices and test data are

- Photographs of test set-up

- Voltage used

- Electrostatic field readings

- positions of all test ESC devices and electrical connections

- Start and stop times of experiments

- Polarities of ESC devices

- Identification of swipe samples from ESC devices

- Photomicrographs of aerosol particles from the SEM.

- The aerosol and filter data to be collected are

- Soil particle size distribution

- $\quad{ }^{239} \mathrm{Pu}$ concentrations (picocuries per gram) in the soil

- Moisture content of the soil

- Flow rate through the aerosolization apparatus

- EPA cyclone sampier flow rate

- $\quad$ Pre-experiment and post-experiment mass of all EPA respirable filters

- Position of EPA cyclone samplers and other apparatus in the enclosure

- Linear air flow in the enclosure

- Air flow in the Hi-Vol 2-in. particulate filter

- $\quad$ Prepost test mass of the 2 -in. filter

- Air pressure in the plastic tubing 
- Parameters such as respirable fraction and ${ }^{239} \mathrm{Pu}$ concentrations in collected respirable and nonrespirable samples (radiochemical analysis and SEM results)

- Photographs of the entire apparatus

- Mass of the collected nonrespirable fraction. 


\section{EQUIPMENT}

The following is a list of equipment for the ESC experiments

- ESC material test samples

- Metal plates

- Conductive sheet material

- Polyethylene sheet

- Electret filter material.

- The electrical and ESC test fixtures will use the following equipment:

- Power supply (300 to $600 \mathrm{~V}$ )

- Ground cable

- Hookup insulated wire

- $\quad$ ESC test fixtures

- Current limiting resistors

- Terminals for making electrical connection to conducting materials

- Conducting tape

- Duct tape.

- The hardware and aerosol test equipment are

- Aerosol generator box and tygon tubing

- Perma-con stainless steel enclosure with input HEPA filters

- Ventilation system and flow duct with output HEPA filter

- $\quad$ Satorius balance, model AS120

- Air supply and hose connections

- $\quad$ Mattheson flowmeters, model 604

- $\quad$ Gast $5 \mathrm{cfm}$ rotary vane pumps 
- $\quad$ MSA cyclone sampler, model 456-243 (i.e., lapel cyclone samplers)

- Ashcroft pressure and vacuum gauges

- Solomat airspeed and humidity meter, model MPM 500e

- Moisture meter composed of a moisture cell (MC-314) and a Soiltest, model 305B, readout

- $\quad$ Electrostatic field meter (SIMCO FM-300 or equivalent).

\subsection{Maintenance and Operation}

Operation of the ESC devices and supporting electrical equipment consists of turning the switches on to supply $300 \mathrm{~V}$ from the electrical power supply to the ESC devices after the electrical hookup has been verified. After the test is completed, the switches are turned off.

Maintenance of the Perma-con enclosure, pumps, and cyclone samplers (used in all the dust movement, distribution, and suppression experiments) is similar for each test. All the loose dust possible is removed from the test enclosure by vacuuming and wiping using the gloves in the glove ports. The filter assemblies are cleaned. The airspeed and relative humidity probes must also be cleaned of dust and moisture. Special assemblies for generating dust are maintained and operated according to these test plans. The operation involves weighing and loading all filters, setting flow rates, and performing manipulations according to specific test plans.

\subsection{Calibration}

The following is a discussion of the various routine calibrations for the instruments described in this document. These calibrations, listed below, meet the data quality objectives and will be recorded in the laboratory notebook with instrumentation serial numbers and calibration data.

- Voltmeter-Voltmeters are calibrated by the EG\&G Idaho, Inc. Calibration Laboratory.

- Mettler and Sartorius Balances-All balances are calibrated before use with internal calibration standards or external (National Institute of Standards and Technology) traceable weights and yearly by the calibration group at the INEL.

- Flowmeters and Pressure Gauges-Flowmeters and pressure gauges are calibrated annually.

- $\quad$ Airspeed and Humidity Probe-The airspeed probe is calibrated at the factory using a windtunnel with better than $1 \%$ accuracy. Calibration is checked annually. The relative humidity probe is calibrated using a bottle with molecular sieve for $<0.5 \%$ and a saturated salt solution for $>75 \%$ relative humidity. The owners manual gives specific instructions for calibration performed as needed or yearly. Factory calibration performed May j, 1988, was to an accuracy of $+2 \%$. 
- Samplers-The samplers (cyclone and 2 in.) are designed for a given flow rate and are calibrated per the manufacturer's recommendations. 


\section{ANALYTICAL PROCEDURES}

\subsection{Radiochemical Plutonium Analysis}

Determination of plutonium concentration is performed using radiochemical separations followed by analysis of the separated fraction using alpha spectrometry. The sample is put into solution with a high temperature fusion followed by acid dissolution. Following a barium sulfate precipitation, the solid is dissolved in alkaline ethylenediaminetetraacetic acid and precipitated as $\mathrm{Ce}\left(\mathrm{OH}_{2}\right)$ for alpha spectrometry. Samples can also be precipitated as neodymium fluoride using the same technique to prepare standards for the alpha constant air monitors. This precipitate is also counted directly on a surface barrier detector.

\subsection{Plutonium Analysis by Large Area Alpha Spectrometry}

Analysis of plutonium in soils and tilters can also be accomplished by large area alpha spectroscopy. Filters and smears are ground sieved, and then mixed with ethanol and sprayed on a plate that is counted directly.

\subsection{Gravimetric Analysis of Filters}

All filters are weighed before and after each test on a $+0.1 \mathrm{mg}$ balance after drying in a desiccator. Blank filters are periodically weighed in sets of 10 to test precision and determine the effect of static charge and temperature on weights. Nonrespirable dust traps are cleaned and weighed before each test. These weights are used to detect any build-up of dust or moisture on the caps. Each filter assembly is labeled and assigned a number. Decontaminated, clean, dry cyclone samplers are assembled using gloves. A new preweighed membrane filter is inserted into holder. The circular screen is placed on the filter, and the filter holder is reassembled. The seam is sealed with a cellulose band and allowed to dry before using the sampler in a test. The preweighed collector cap is screwed onto the cyclone body. Fiberglass filters are placed on an attachment ring, and the assembly is sealed with a rubber gasket. After each test, the cascade impactor and low volume (Lo-Vol) filters and cyclone collector caps and filters on a calibrated $+0.1 \mathrm{mg}$ balance are carefully retrieved and weighed. Total concentration, respirable, and nonrespirable fraction of airborne dust can then be calculated from the flow data. After weighing, clean cyclone filters, cyclone caps, and cascade impactor removable parts are placed in a desiccator for subsequent experiments.

\subsection{Calculation Procedures}

A decontamination factor will be determined from the experiment data for the electrostatic separator (plates), CRT, and electret filter. The input and output cyclone sampler filters from the ventilation system test section will be used to determine how much ${ }^{239} \mathrm{Pu}$ is removed by the various ESC devices (e.g., plates, CRT, and electret). The ${ }^{239} \mathrm{Pu}$ removal efficiency (decontamination factor) can be determined by

Removal efficiency $\%=\left[\left(\mathrm{P}_{\text {in }}-\mathrm{P}_{\text {out }}\right) / \mathrm{P}_{\text {in }}\right] * 100$ 
where

$$
\begin{aligned}
& \mathrm{P}_{\text {in }}=\mu \mathrm{Ci} / \mathrm{mg} \text { of }{ }^{239} \mathrm{Pu} \text { on input filter } \\
& \mathrm{P}_{\text {out }}=\mu \mathrm{Ci} / \mathrm{mg} \text { of }{ }^{239} \mathrm{Pu} \text { on output filter. }
\end{aligned}
$$

Design calculations for plate size, separation distance, and voltage used in the separator will be verified by the experiment data. The particle mass data and results of the radiochemical analysis will be presented in tables and bar graphs with the statistics of arithmetic mean and standard deviation shown.

The measured amounts of dust and ${ }^{239} \mathrm{Pu}$ from coupons of the different materials will be compared to determine the effectiveness of grounding the conducting materials as compared to the polyethylene (insulation material). A decontamination factor that shows the effectiveness of using grounded conducting materials verses insulating materials will also be determined. This calculation is similar to the separator removal efficiency and is

Material decontamination factor $\%=[(\mathrm{IM}-\mathrm{CM}) / \mathrm{IM}] * 100$

$$
\begin{aligned}
& \mathrm{IM}=\mu \mathrm{Ci} / \mathrm{mg} \text { of }{ }^{239} \mathrm{Pu} \text { on insulation material } \\
& \mathrm{CM}=\mu \mathrm{Ci} / \mathrm{mg} \text { of }{ }^{239} \mathrm{Pu} \text { on grounded conductor material. }
\end{aligned}
$$




\section{DATA MANAGEMENT AND ANALYSIS}

The data management and analysis include data reduction, validation, recording, and calculations. The first three are discussed together in the next section.

\subsection{Reduction, Validation, and Recording}

The data will be assembled, analyzed, and documented in EG\&G Idaho informal reports. Validation of the data will be ensured by following this document. Qualification of the data will be conducted by the analysis team and will be approved by the analysis team leader. Specific data reported include

- Amount of contamination collected on ESC devices and reported in (picocuries per gram) of sample collected

- Ratio of plutonium to nonradioactive particles collected

- Photomicrographs of collected particles from the SEMs

- Particle size distribution

- Measurement of mass of dust collected on filters and coupons.

The major points in the report are

- Discussion of the enclosure materials, their electrical properties, and use in contamination control

- Efficiency of the electrostatic plates in removing ${ }^{239} \mathrm{Pu}$ particles from an aerosol

- Use of stronger electrostatic field sources, such as a CRT, in attracting radioactive particles

- Size distribution of particles that stick to the ESC devices

- Estimate of plutonium particle size distribution with the cascade impactor and SEM

- $\quad$ Efficiency of electret filters in removing submicron size radioactive particles.

\subsection{Data Calculations}

During the ESC tests, the total airborne dust collected with the cyclone samplers or the Anderson cascade impactor will be used to compare with the dust collected on the ESC devices. The total mass of dust collected on each sampler filter will be divided by the total volume of air sampled to determine airborne dust concentrations. 
Air and soil concentration detection limits for monitoring activities can be estimated. Potential surface contamination concentrations possible from a given air concentration depend on the particular settling factors used and any partitioning of the contamination onto certain particle sizes. Calculating the reverse of this, potential air concentration from a given soil concentration, depends on the resuspension factor of the particles with attached contaminants. For example, using a derived air concentration of $2 \times 10^{-12} \mu \mathrm{Ci} / \mathrm{cm}^{3}$ and a dust concentration of $1 \times 10^{-7} \mathrm{~g} / \mathrm{cm}^{3}$ provides a dust activity level of $20 \mathrm{pCi} / \mathrm{g}$. If soil, at the minimum concentration classified at TRU contaminated soil of $100 \mathrm{nCi} / \mathrm{g}$, is fully suspended in the air to a concentration of $1 \times 10^{-7} \mathrm{~g} / \mathrm{cm}^{3}$, the air concentration becomes $1 \times 10^{-8} \mu \mathrm{Ci} / \mathrm{cm}^{3}$ or one half the maximum permissible level for bubble suit entry given a protection factor of 10,000 . 


\section{QUALITY ASSURANCE}

Most of the experiments will be performed a minimum of three times or multiple samples collected to determine the reproducibility of the results. The requirements lor quality assurance in evaluating the ESC tests have been discussed in Sections 4, 5, and 7. These included sampling procedures, sample control, equipment, and analytical procedures. The radiochemical analysis will follow standard procedures for the radiochemistry laboratory and the uncertainties reported with the results. Quality assurance measures for sampling include special container or coupon washing, verification of contamination free filters and smears, proper sample packaging and preservation, chain of custody control, and prompt analysis. This test plan and the test results, including the analysis, will be independently reviewed by a knowledgeable person in electrostatics and analytical procedures to ensure data integrity. Radiation measurements personnel and the RADCON engineer will also review the test plan and support the tests as needed. 


\section{SAFETY, TRAINING, AND LOGISTICS}

Safety is of utmost concern with all experiments. It is the policy of EG\&G Idaho to take every practical precaution to protect the health of the employees. Three types of safety and training concerns are emphasized: radiological, laboratory, and waste management.

\subsection{Radiological Safety and Training}

Radiological safety and conformance to the EG\&G Idaho Radiological Controls Manual ${ }^{6}$ will be ensured by consulting on-duty RADCON personnel before experiments using radioactive materials. Subsections of the manual that apply to this document include

- $\quad$ Chapter 3, "Airborne Radioactivity Limits, HEPA Filter Requirements, Monitoring for Airborne Radioactivity"

- Chapter 4, "Enclosure for Containing Contamination and Severe Measurements"

- Chapter 8, "Constant Air Monitors, Instrument Calibration and Control, Selection and Installation of Continuous Air Monitors"

- Chapter 11, "Continuous Availability of RADCON Personnel, Inspecting Radiological Work, Planning Radiological Controls, Radiation Worker Training, Radiological Controls, Review and Approval."

\subsection{Laboratory Safety and Training}

Laboratory safe practices are described in the Science and Technology Standard Practices Manual, Section $2 .^{7}$ Subsections that apply to this document in Section 2.1, "General Laboratory Practices" include

- 2.1.5-"Eye Protection and Protective Clothing"

- $\quad$ 2.1.6-"Laboratory Safety"

- 2.1.8-"Laboratory Hood Use"

- 2.1.10-"Hydrofluoric Acid Use."

Subsections that apply to Section 2.2, "Site Laboratory Practices," include

- 2.2.4-"Radioactive Materials Handling"

- 2.2.5-"Glove Box Use"

- 2.2.7-"Laboratory Radiological Training." 
Temporary or experimental circuits shall comply with the EG\&G Idaho Safety Manual, ${ }^{8}$ Section 10.4. Subsections of Section 10.4 that apply to this test plan include

- 3.4-"Guards and Enclosures"

- 3.4-"Equipment or Experiment Disconnects."

\subsection{Waste Management Practices and Training}

Waste management practices are prescribed in the EG\&G Idaho Safety Manual, ${ }^{8}$ Section 15, and Section 2 of the Science and Technology Standard Practices Manual. ${ }^{7}$ Subsections of Section 2 of the Science and Technology Standard Practices Manual that apply to this document include

- 2.1.1-"Non-Radioactive Chemical Waste Disposal"

- 2.1.3-"Chemical Lab Inventory"

- 2.1.4-"Chemical Spill Control"

- 2.2.9-"Handling and Storage of Hazardous Waste in Satellite Accumulation Areas."

Pertinent subsections in the Safety Manual, Section 15, "Waste Management," include

- 2-"Incinerable Low-Level Radioactive Waste"

- 3-"Compactible Low-Level Radioactive Waste"

- 9--"Transuranic Waste"

- $\quad$ 15.1-"Routine Solid Waste Collection and Handling." 


\section{RISK ANALYSIS}

The risk analysis for lockout and tagout, radiological hazards, electrical hazards, sample handling, and sample transportation between the experiment location and analysis laboratory are assessed in this section.

\subsection{Lockout and Tagout}

The radiological hazards will be assessed by the RADCON engineer, and recommendations will be followed with regard to any lockout and tagout required for personnel radiological protection. The electrical power supply for plate voltage and the CRT are standard $110 \mathrm{~V}$ plug connected equipment and do not require lockout or tagout. They will only be turned on for the run time of the experiment in which they are used. The run time will be approximately 15 to 20 minutes for each part of the experiment.

\subsection{Radiological}

The radiological hazards will be assessed by the RADCON engineer, and recommendations will be followed with regard to any radiation zones, special handling, or anti-contamination clothing required for personnel protection. Existing alpha constant air monitors will be used in areas where personnel are present during the experiments. The need for a safe work permit will be determined by the TRA RADCON engineer.

\subsection{Electrical}

The electrical power supply for plate voltage and CRT are standard $110 \mathrm{~V}$ plug connected equipment and will only be turned on for the run time of the experiment in which they are used. At the conclusion of each part of the experiment, the power supply will be turned off and power leads shorted before removing samples. The cables running to the parallel plates will have resistors in a series to limit any short circuit current to less than $10 \mathrm{~mA}$. The power supplies also have current limiting settings. The voltage on the plates may be varied between $100 \mathrm{~V}$ and $600 \mathrm{~V}$. The maximum energy stored in the parallel plate arrangement is 0.385 millijoules (based on $276 \times$ 24-in. plates spaced $1 \mathrm{~cm}$ apart with $600 \mathrm{~V}$ applied). The Perma-con enclosure, conducting fabric, and odd numbered plates will be grounded. Electret filters have permanently polarized fibers and are not a personnel electrical hazard.

\subsection{Sample Handling}

Sample coupons and sampler filters will be placed in preweighed petri dishes and removed through glove ports. The petri dishes with the sample will then be weighed and placed in plastic bags, sealed, and stored in the Perma-con enclosure or other location as approved by the RADCON engineer. 


\subsection{Transportation Between Experiment and Laboratory}

The bags containing the petri dishes with the samples will be hand carried to the radiochemistry laboratory or SEM laboratory for analysis. The SEM laboratory is in the basement of MTR-654, and the experiment will be performed in the laboratory, room 101, in MTR-654. The radiochemistry laboratory is in the adjoining building 604 . 


\section{REFERENCES}

1. L. C. Meyer, Transuranic Contamination Control Using Electrostatic Curtains (Proof-Of-Principal Experiments), EGG-WTD-9336, November 1990.

2. L. C. Meyer, Electrostatic Curtain Studies, EGG-WTD-10255, May 1992.

3. L. C. Meyer, Preconceptual Design for the Electrostatic Enclosure. EGG-WTD-10450, September 1992.

4. G. G. Loomis, D. E. Menkhouse, and D. W. Scott, "A System to Control Contamination During Retrieval of Buried TRU Waste," Waste Management 90, Tucson, Arizona, February 25-March 1, 1990.

5. R. A. Fjeld and T. M. Owens, "The Effect of Particle Charge on Penetration in an Electret Filter," IEEE Transactions on Industry Applications, 24, 4, July-August 1988, pp. 725-730.

6. EG\&G Idaho, Inc., Radiological Controls Manual.

7. EG\&G Idaho, Inc., Science and Technology Standard Practices Manual.

8. EG\&G Idaho, Inc., Safety Manual. 

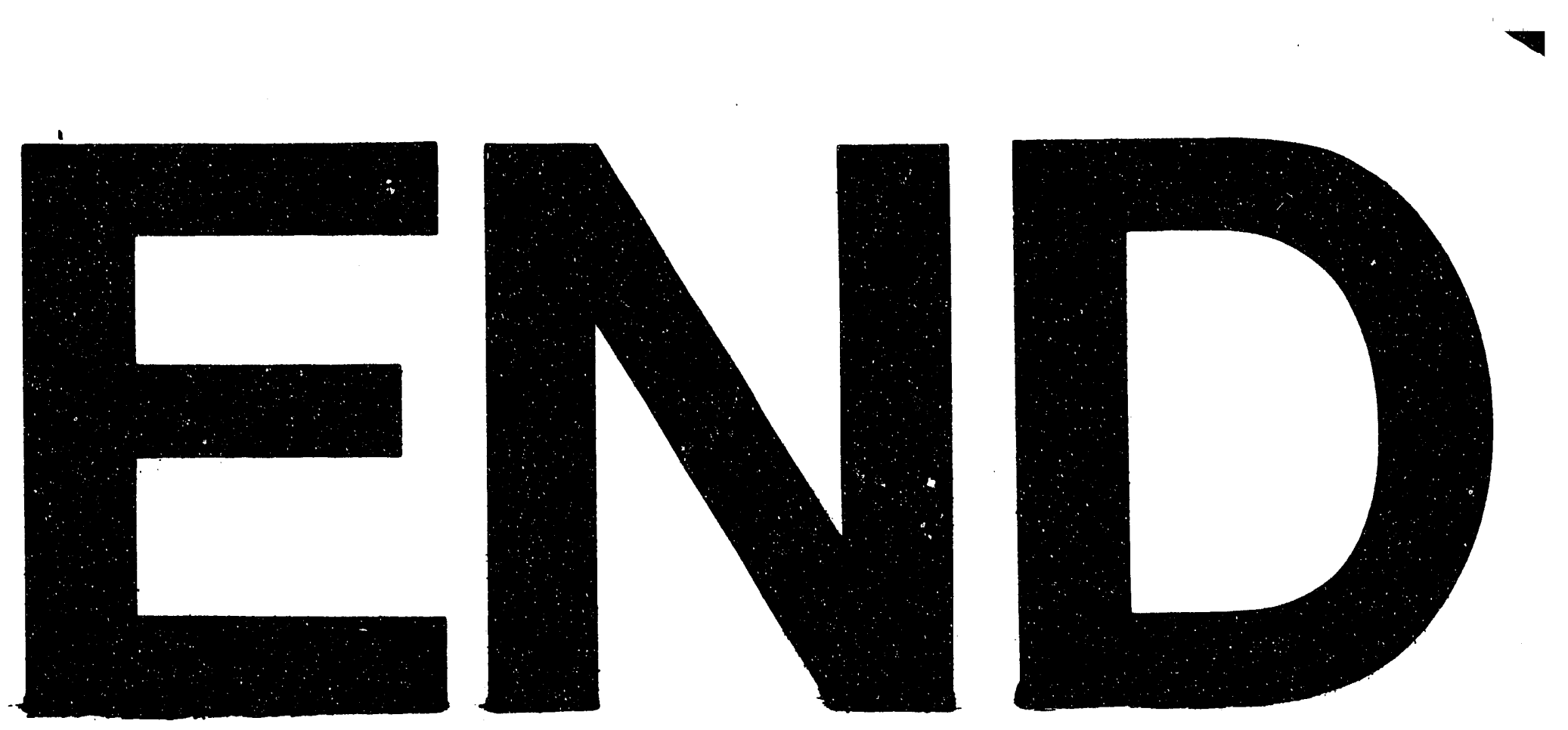

$x$

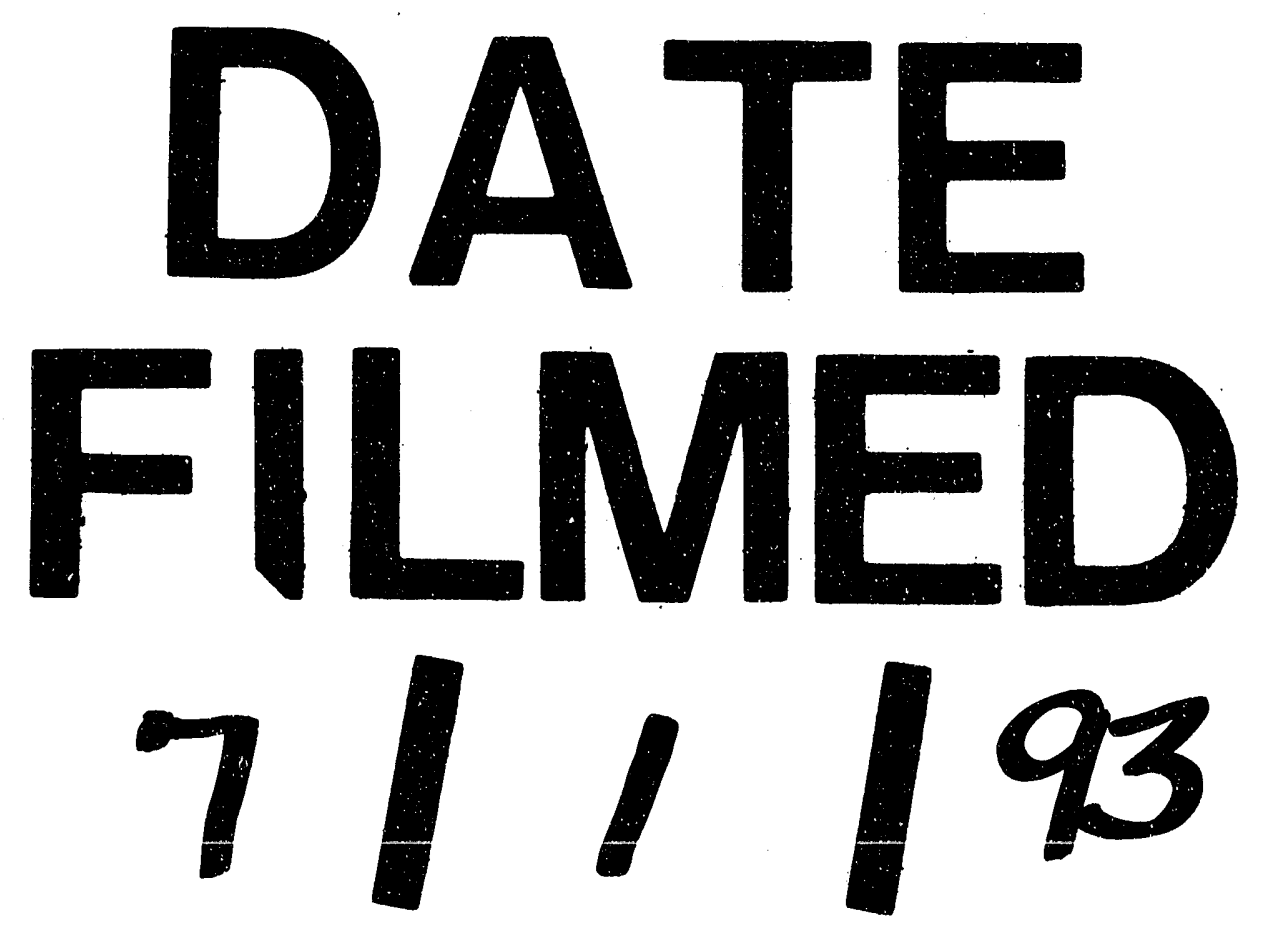


